\title{
A INCIDÊNCIA E A INSISTÊNCIA DA VERDADE NO DISCURSO: NOTAS PARA RELER A VONTADE DE SABER
}

\author{
Marluza T. da Rosa* \\ Universidade Estadual de Campinas \\ Instituto de Estudos da Linguagem \\ Campinas, São Paulo, Brasil
}

\begin{abstract}
Resumo: Neste ensaio, propomos um percurso de leitura que incide sobre a relação, frequentemente tida como ambivalente, entre Foucault e a psicanálise. Partimos da crítica desenvolvida pelo autor em A vontade de saber, buscando articular a problemática da produção da verdade à incidência e à insistência do/no discurso. Tal articulação permite reafirmarmos que é porque há demanda de um dizer exaustivo, e em dadas condições, que o sujeito e a verdade, em termos psicanalíticos, emergem, o que nos leva a compreender não só que as verdades de nosso tempo e de nossa sociedade são perpassadas pela experiência fundamental da linguagem, mas também que elas são, em grande medida, produzidas por campos de saber, não preexistindo, assim, ao discurso.
\end{abstract}

Palavras-chave: Discurso. Psicanálise. Verdade.

1 INTRODUÇÃO

A publicação, em 1976, de $A$ vontade de saber, primeiro volume de História da sexualidade, instaura um movimento de análise e de crítica da contemporaneidade que afeta, desestabiliza e provoca discussões acerca dos preceitos de diversas disciplinas, como a história, a filosofia e as chamadas ciências psi. Nessa obra, Foucault propõe que se reconsidere a denominada hipótese repressiva freudo-marxista - segundo a qual o sexo é reprimido para que o indivíduo se torne cada vez mais produtivo -, destacando, desde as primeiras páginas, a fragilidade dos pressupostos dessa hipótese, os quais, para o autor, são fáceis de sustentar, visto que se ancoram em evidências historicamente construídas.

Ao colocar em pauta a problemática da produção da sexualidade, o referido texto leva-nos a refletir para além da superfície desse e de outros discursos socialmente aceitos, permitindo-nos a compreensão de seu processo de constituição, bem como de seus possíveis efeitos sobre o sujeito. Essa empreitada marca o início da fase dita genealógica do pensamento foucaultiano, segundo Gros (2004, s. p.), na medida em que "se trata de reencontrar, como matriz de discursos verdadeiros, dispositivos de poder. $\mathrm{O}$ conceito de 'vontade de saber' serve para enquadrar essas análises”". Em tal abordagem,

\footnotetext{
* Doutora em Linguística Aplicada pela UNICAMP. Pesquisadora colaboradora (PNPD/CAPES) no IEL/UNICAMP. Email: marluza.rosa@gmail.com.

${ }^{1}$ « il s'agit de retrouver, comme matrice des discours vrais, des dispositifs de pouvoir. Le concept de 'volonté de savoir' sert à cadrer ces analyses. »
} 
Foucault não deixa indene a psicanálise tampouco o papel do analista, que se apoia no silêncio para que o outro, o analisante, possa falar e para que certa verdade possa emergir. Assim, A vontade de saber dirige às ciências psi e, consequentemente, à psicanálise, uma crítica severa, inscrevendo esta última em mecanismos de poder que derivam da técnica cristã da confissão, a qual embasa diversos discursos que incidem sobre o indivíduo e sobre seu corpo de modo a governá-los. Todavia, tal herança não consiste em uma evolução linear ao longo da história, mas em uma rede complexa de práticas e de discursos interdependentes.

A crítica desenvolvida em $A$ vontade de saber é conhecida por marcar um momento de ruptura na leitura que o autor desenvolve sobre o domínio psicanalítico. Se, em As palavras e as coisas, publicado em 1969, Foucault considera a psicanálise como uma "contra-ciência", ou seja, como uma ciência crítica que vai à contracorrente em relação às demais, em $A$ vontade de saber, a constituição desse domínio de saber recebe um olhar mais cauteloso, visto que, nos termos de Foucault (1988, p. 141), "em sua emergência histórica, a psicanálise não pode se dissociar da generalização do dispositivo de sexualidade e dos mecanismos secundários de diferenciação que nele se produziram", apesar de, diferentemente da psiquiatria e da medicina, essa prática modificar o papel e o funcionamento da sexualidade.

Na relação que estabelece entre Foucault e Lacan, Mendelsohn (2010) aponta três fases da leitura/crítica foucaultiana à psicanálise: a primeira, em que o filósofo reconhece, na empreitada freudiana, um eco de suas próprias problemáticas, como as questões da normatividade médica e da consciência; a segunda, em que a psicanálise passa a ser encarada como parte de dispositivos de normalização; e a terceira, em que o autor reconhece na psicanálise lacaniana uma preocupação com o questionamento de uma metafísica do sujeito solidificada desde Descartes. Embasam-se, principalmente, no segundo momento as leituras que tomam ambos os autores como inconciliáveis. Contudo, é inegável que preocupações semelhantes, como "a relação do sujeito com o saber e a verdade" (CAMARGO; AGUIAR, 2009), aproximam Foucault e Lacan, guardando-se, sem dúvida, as especificidades da obra de cada autor. A respeito desse (des)encontro, Roudinesco (2007, p. 108-109) salienta que, "embora Lacan não fosse foucaultiano por antecedência, estava mais bem preparado que os psiquiatras de sua geração para aceitar as teses de História da loucura". Também, seu "retorno a Freud" pode ser associado a sua presença, como ouvinte, na conferência "O que é um autor?", proferida por Foucault, na qual este trata do "retorno a...", compreendendo Freud e Marx como fundadores de discursividade (GOLDENBERG, 2012). Atualizando esse debate, Milner também se manifesta, argumentando que o olhar geralmente cético que Foucault direciona à psicanálise não significa uma rejeição do pensamento de Freud ou de Lacan, pois, para o autor, “o julgamento de Foucault sobre Freud ou sobre Lacan não seria equivalente a seu julgamento a respeito da psicanálise como prática, como instituição ou como doutrina" (MILNER, 2011, p. 100).

Levando em consideração essas especificidades, neste estudo abordaremos a discursivização enquanto procedimento de produção de verdade, tendo como ponto de partida a leitura de $A$ vontade de saber. Tal percurso se justifica pela possibilidade que nos oferece não somente de explorar o pensamento teórico de Foucault, mas também de 
melhor compreender sua relação conflituosa com as ciências psi, em especial com a psicanálise e sua forma particular de produzir a verdade. Por sabermos que, a partir de Freud, essa prática é instituída como uma talking cure, ou seja, uma cura pela palavra, desenvolveremos esta proposta, tomando a exigência em se dizer como fio condutor, o que contribui para os trabalhos na área dos estudos discursivos, na medida em que lança um olhar sobre a noção de discurso, sobre a problemática dos discursos institucionais, bem como sobre possíveis objetos de análise.

\section{VERDADE: EFEITO DE UMA DUPLA INSISTÊNCIA}

Ao longo de toda sua obra, a tomada de posição foucaultiana se dá em relação a discursos, o que implica considerar que seu olhar se dirige a um conjunto de regras de formação que permitem a constituição de (um ou mais) objetos de estudo. No caso de $A$ vontade de saber, trata-se do discurso moderno da repressão do sexo. Já em $A$ arqueologia do saber, o autor definia o discurso como uma rede ou um feixe de relações designadas práticas discursivas, e pensar sobre essa noção não consiste em tratar de uma relação entre forma e conteúdo nem entre palavras e coisas (língua e realidade). Segundo Foucault (2009, p. 55), o discurso tampouco deve ser visto como um jogo entre signos linguísticos, "mas como práticas que formam sistematicamente os objetos de que falam".

Consequentemente, não é possível dissociar a realidade do discurso que a circunscreve, pois é por meio dele que esta ganha existência. A sexualidade, por exemplo, cuja história Foucault se propõe a escrever, vista como ponto de junção entre o sujeito, o discurso e a verdade (MENDELSOHN, 2010), não existe fora de uma rede de enunciados ou de um conjunto de regras que a determinam e do qual fazem parte discursos como o da pastoral cristã, da medicina, da psicanálise, dentre outros. Propor uma arqueologia desses saberes, como argumenta Gros (2004, s. p.), "supõe então um primeiro distanciamento crítico dos enunciados positivos estabelecidos, terminais e definitivos, 'científicos e verdadeiros', uma neutralização de sua potência de esclarecimento retrospectivo",

Para isso, deve-se compreender que, em um mesmo sistema de formação, podem coexistir teorias dissonantes ou mesmo em conflito, o que não anula o fato de estas terem uma base em comum. No que concerne à psicanálise, apesar de esta assumir uma posição reticente frente ao funcionamento do discurso religioso, o que autoriza Lacan (2005, p. 72) a afirmar que "a religião é feita para curar os homens, isto é, para que não percebam o que não funciona”, seu estatuto, enquanto campo complexo de conhecimentos, é atrelado, por Foucault (1988, p. 17), a um funcionamento discursivo semelhante e inscrito na "mesma rede histórica daquilo que denuncia". No entanto, o filósofo, do mesmo modo que não busca invalidar, mas ressituar a hipótese repressiva em suas condições de produção históricas, desenvolve uma releitura da psicanálise que tem por objetivo interrogá-la em seu caráter não-universal, considerando os efeitos que

\footnotetext{
2 «suppose donc une première mise à distance critique des énoncés positifs établis, terminaux et définitifs, 'scientifiques et vrais', une neutralisation de leur puissance d'éclairement rétrospectif ».
} 
mecanismos históricos de poder, bem como um dispositivo de sexualidade, produzem ao sustentá-la como discurso da verdade. Em outros termos, podemos dizer que o que Foucault potencializa é uma leitura que prioriza o não-todo da psicanálise, o que, pelo mesmo movimento, permite afirmá-la como uma teoria "verdadeira", pois, nos termos de Milner (2014, p. 115), uma teoria só é verdadeira se for "potente quanto ao nãotodo".

Por meio dessa leitura, é inevitável que certos limites da abordagem psicanalítica sejam apontados, tais como a própria noção de verdade como construção, narrativa, ficção de si, efeito de sentido, mas submetida a mecanismos de poder; margens que, no entanto, longe de inviabilizá-la, servem para circunscrevê-la como um campo do saber. Campo este que se configura, a cada crítica, como condição de possibilidade da própria reflexão foucaultiana, como soube apontar Derrida (1994), fazendo justiça a Freud. Consequentemente, é para a construção histórica da psicanálise e da própria verdade que o olhar de Foucault guia-nos, pois, nos termos de Milner (2014, p. 15), "nosso tempo forjou uma doutrina da verdade" e, de acordo com essa doutrina, continua o autor, "não só é possível que a verdade proceda da inexatidão, mas é preciso sustentar que a inexatidão é a própria forma da verdade" 3 . Essa concepção, uma das quais ancora o retorno lacaniano a Freud, não é em nada evidente, e o percurso foucaultiano pode nos dar subsídios para melhor compreendê-la.

Em "Sexualidade e poder", conferência pronunciada dois anos após a publicação de $A$ vontade de saber e considerada como um texto que marca a passagem para a última fase de seu pensamento, Foucault afirma que o projeto de uma história da sexualidade não vai de encontro à psicanálise, contudo

\begin{abstract}
é preciso tentar verificar em que medida a própria psicanálise, que se apresenta justamente como fundamento racional de um saber sobre o desejo, como a própria psicanálise faz parte, sem dúvida, dessa grande economia da superprodução do saber crítico a respeito da sexualidade (FOUCAULT, 2010, p. 60).
\end{abstract}

Trata-se, evidentemente, de uma visada crítica direcionada à psicanálise como ciência do sujeito, com pressupostos teóricos e práticos, mas sobretudo como discurso, na medida em que, segundo o autor, "a história da sexualidade [...] deve ser feita, antes de mais nada, do ponto de vista de uma história dos discursos" (FOUCAULT, 1988, p. 78), e o discurso psicanalítico, indubitavelmente, exerce um papel importante nessa história. É a partir dessa relação que podemos compreender por que Foucault concebe os postulados terapêuticos das ciências psi, inclusive os da psicanálise com sua talking cure, como tendo sua matriz na prática cristã da confissão. É sobre esse aspecto que vamos nos deter a partir de agora, pois, antes de se considerar que "a psicanálise é apenas um dos mais recentes elos da longa cadeia da confissão que atravessa a história da sensibilidade ocidental"4 (BURGUIERE, 2013, p. 143), é importante observar como essa rede se estrutura.

\footnotetext{
3 « notre temps a forgé une doctrine de la vérité [...] il est non seulement possible que la vérité procède de l'inexactitude, mais il faut tenir que l'inexactitude est la forme même de la vérité »

4 «la psychanalyse n'est que l'un des plus récents maillons de la longue chaîne de l'aveu qui traverse l'histoire de la sensibilité occidentale ».
} 
Se é verdade que, enquanto doutrina, a psicanálise pode ser vista como o resultado ou até o triunfo da pastoral cristã (SENELLART, 2013), isso se deve ao fato de esse núcleo de poder ter sido estabelecido como o ponto de partida de Foucault. A esse respeito, dois aspectos merecem ser considerados. Primeiramente, a questão da sexualidade como sendo passível de repressão, de (de)negação, de recalcamento e, ao mesmo tempo, como possibilidade de verdade do sujeito. Uma verdade que, segundo Milner (2014),

\begin{abstract}
não é um predicado, ela é sujeito; mais exatamente, ela surge a partir do instante em que o sujeito insiste em um falar. Não sendo, então, predicado, ela é efeito dessa insistência. Que o efeito opere naquele que fala ou naquele que ouve, pouco importa. Uma vez disjunta da exatidão, a verdade se torna efeito de verdade ${ }^{5}$ (MILNER, 2014, p. 19).
\end{abstract}

Daí decorre o segundo aspecto: tal verdade, para se produzir enquanto efeito, está condicionada ao fato de não dizer do sujeito senão quando submetida a certas circunstâncias ou condições de produção. Em outros termos, não basta apenas falar de si, deve-se, além disso, dizê-lo a um indivíduo particular e em condições específicas. $\mathrm{Na}$ análise proposta por Foucault, a posição de quem ouve e dirige as consciências, assim como o lugar em que o falar de si se dá, sofre modificações no tempo e nos espaços: do confessionário, à família, ao consultório médico, ao terapeuta, ao analista...

À pergunta o que se deve dizer? responder-se-ia, primeiramente, tudo: "os crimes, os pecados, os pensamentos e os desejos, confessam-se passado e sonhos, confessa-se a infância; confessam-se as próprias doenças e misérias" (FOUCAULT, 1988, p. 68). Já aqueles que sabem que "tudo não pode ser dito", que a verdade apenas se semidiz, responderiam: qualquer coisa, pois não se trata de uma confissão, não haverá nenhum julgamento ou punição, apenas fale. E, na injunção a interpretar, a produzir sentidos e saberes, mesmo o silêncio, dependendo do momento e do que se acredita calar, também significa. Quem cala consente.

Para Foucault, essa insistência no fazer falar ou, diríamos, no fazer significar, ancora-se em um conjunto de mecanismos de poder que não estão livres dos imperativos (morais, políticos, ideológicos) de uma época. Mecanismos estes que não se referem a um poder repressivo ou proibitivo, mas a seu avesso, pois, em suas palavras, "é necessária uma representação muito invertida do poder, para nos fazer acreditar que é de liberdade que nos falam todas essas vozes que há tanto tempo, em nossa civilização, ruminam a formidável injunção de devermos dizer" (FOUCAULT, 1988, p. 69). O desafio é sobretudo o de não se iludir ao pensar que o dizer ou o saber são contrários ao poder ou que as ciências psi, por serem ciências, funcionam de forma neutra e libertadora, e não como engrenagens dos dispositivos de poder que nos normalizam.

Assim, é por vivermos em uma sociedade que nos condicionou a e pela confissão, é por acreditarmos que somos mais livres quando falamos do que quando calamos, que

\footnotetext{
${ }^{5}$ «la vérité n'est pas un prédicat, elle est sujet; plus exactement, elle surgit dès l'instant que le sujet insiste dans un parler. En tant donc qu'elle n'est pas prédicat, elle est effet de cette insistance. Que l'effet opère chez celui qui parle ou chez celui qui entend, peu importe. Une fois disjointe de l'exactitude, la vérité devient effet de vérité ».
} 
repetimos discursos tais como o da repressão sexual, de que trata Foucault (1988). De modo semelhante, é por acreditarmos que o falar nos fará bem e que estaremos mais próximos de nos livrarmos de nossas doenças, vícios e fraquezas ao admiti-los, que fazemos e demandamos confissões. No que concerne à sociedade contemporânea, também chamada de pós-moderna, acredita-se haver muito a confessar: é preciso admitir que somos dependentes químicos, que estamos fora do peso, que somos depressivos, que estamos perdidos e/ou que precisamos de alguém que nos oriente. Hoje, podemos falar abertamente sobre nossa sexualidade (ou seria esse um imperativo?), já classificada e naturalizada. Logo, quem fala é quem consente, na medida em que se insere na e se submete à engrenagem da produção de discursos, de saberes e de sentidos.

O que não sabemos ou queremos não saber é que funcionamos como o louco da situação rememorada por Foucault na conferência "Subjetividade e verdade", em 1980. Trata-se do seguinte exemplo:

Em uma obra reconhecida sobre o tratamento moral da loucura, publicada em 1840, um psiquiatra relata de que modo tratou e acredita ter curado um de seus pacientes, senhor A. Ele o coloca sob uma ducha fria, fazendo-o admitir que as vozes que ouve e os inimigos que vê são frutos de sua insanidade. Segundo Foucault, este é um mecanismo antigo, que ignora o que pensa o paciente, visando a apenas extrair dele uma confissão: "sou louco", o que, evidentemente, não significa que tal paciente deixe de sofrer. No exemplo dado, senhor A, depois de muitas duchas, reconhece que é louco, como queria o médico, no entanto, acrescenta: "reconheço, porque você me força a fazê-lo" (FOUCAULT, 2013, p. 31), a que o psiquiatra responde com novos banhos frios. Diferentemente deste paciente, porém, nem sempre resistimos ou reagimos, proferindo as palavras finais. Nem sempre esgotamos a linguagem em seu querer dizer ou nosso interlocutor, em seu querer ouvir. Talvez, porque sequer suspeitemos do princípio que nos faz falar (a língua é simplesmente fascista, diria Roland Barthes), talvez porque seja menos problemático não confrontar a instância que nos subjuga, que nos pega pela língua.

Esses mecanismos de poder que insistem sobre o dizer a verdade, segundo a leitura foucaultiana, foram instituídos pelo regime pastoral e serviram de base para as técnicas modernas de análise e de controle individual, pois a pastoral cristã metaforicamente representada na figura de um pastor que guarda seu rebanho - não é senão uma aparelhagem discursiva fundada sobre a vigilância dos indivíduos de um grupo. Esse funcionamento, para Foucault, é individualista e não global, pois o bom pastor deve poder recuperar cada ovelha perdida da tropa, ou seja, cada indivíduo em particular. No entanto, o ideal dessa metáfora só se concretiza se os integrantes do grupo exercerem bem seu papel de "ovelhas", obedecendo ao pastor e lhe expondo suas ações, seus desejos, seus pensamentos, mesmo os mais secretos, a fim de que possam ser guiados.

Contemporaneamente, não é preciso uma análise muito aprofundada para percebermos que uma série de lugares nos faz constantemente essa demanda, implícita

\footnotetext{
${ }^{6}$ « Subjectivité et vérité ».
} 
ou explicitamente: no consultório médico (“o que você está sentindo?"), nas redes sociais ("no que você está pensando?"), nos anúncios publicitários (“o que você faz para ser feliz?") ou quando tentamos nos livrar deles (“por que você ocultou este anúncio?”). Mas, respondemos a questões dessa ordem? Para qual interlocutor? Seu funcionamento estaria atrelado à possibilidade de uma interpretação/ressignificação de si?

Em sua configuração inicial, segundo Foucault, a estratégia da confissão permanente consiste em uma prática específica do cristianismo, por meio da qual

o cristão deve confessar incessantemente tudo o que se passa nele a alguém que estará encarregado de dirigir a sua consciência, e essa confissão exaustiva vai produzir de algum modo uma verdade, que não era certamente conhecida pelo pastor, mas que tampouco era conhecida pelo próprio sujeito (FOUCAULT, 2010, p. 70).

Como podemos notar, trata-se de um mecanismo cujo modus operandi, procedendo por repetição, produz um saber e, igualmente, uma verdade sobre o que e sobre quem se diz. Esse saber ou essa vontade de saber engendra uma maquinaria de poder: de um lado, há uma incitação institucional a examinar sua consciência e a tudo dizer. De outro, há um indivíduo que, confrontado a essa demanda e, igualmente, à sexualidade, apresentada pela pastoral cristã como "o enigma inquietante" (FOUCAULT, 1988, p. 41), fala cada vez mais. Quando Foucault se refere ao sexo como "l'inquiétante énigme" (FOUCAULT, 1976, p. 48), é o eco de "l'inquiétante étrangeté", do qual trata Freud (1933), que pode ser ouvido, na medida em que o mais próximo, o mais íntimo, é também o mais estranho, o que foi recalcado e que retorna. Dito de outro modo, nos termos de Foucault (1988, p. 69), "o que escondemos e o que se oculta, o que não pensamos e o que pensamos inadvertidamente", o que pensamos não pensar. Porém, o autor dirige a esse aspecto um olhar ao revés, pois não admite esse esquema psíquico que lhe parece evidente ou, ao menos, bem aceito, colocando-o em xeque. Em uma entrevista realizada em 1980, Foucault (2013, p. 151) responde do seguinte modo a questão sobre um querer inconsciente: "não sei o que é uma vontade inconsciente. O sujeito de vontade quer o que quer e, a partir do momento em que você introduz nele uma clivagem que consiste em dizer: 'você não sabe o que quer. Eu vou lhe dizer o que você quer', é evidente que é um dos meios fundamentais para exercer o poder" $"$.

Ora, não se observa aí uma recusa do inconsciente, tampouco uma insistência sobre a reafirmação do sujeito cartesiano, como se pode ser levado a pensar. $O$ incômodo que parece se delinear na resposta foucaultiana consiste no uso de um dispositivo teórico (psicanalítico, psicológico, filosófico, pouco importa) como forma de poder, como meio de constituir uma ciência do sujeito ou uma ciência da sexualidade. Assim, se retomarmos o excerto de Milner (2014) mencionado

\footnotetext{
${ }^{7}$ No original: «ce qu'on cache, et ce qui se cache, ce à quoi on ne pense pas et ce qu'on pense ne pas penser »

${ }^{8}$ Tradução nossa para: «je ne sais pas ce que c'est qu'une volonté inconsciente. Le sujet de volonté veut ce qu'il veut, et à partir du moment où vous introduisez en lui un clivage qui consiste à dire: 'tu ne sais pas ce que tu veux. Moi, je vais te dire ce que tu veux', il est évident que c'est un des moyens fondamentaux pour exercer le pouvoir ».
} 
anteriormente, podemos entender que, para que essa verdade - que é sujeito e que "surge a partir do instante em que o sujeito insiste em um falar" - surja, de fato, é preciso que tenha havido uma insistência para que se falasse, a qual é aparelhada no discurso e no campo psicanalítico. Consequentemente, a verdade pode ser considerada como efeito, não de uma, mas de uma dupla insistência, pois é somente a partir da demanda por um falar permanente e exaustivo, que podem insistir, emergir, fazer furo no dizer, o sujeito e sua verdade, em termos psicanalíticos.

No que concerne à primeira insistência, essa aparelhagem instaura um controle exercido sobre o indivíduo, não somente porque o leva a acreditar que está diante de um sujeito suposto (já) saber e, por isso mesmo, pode/deve dizer exaustivamente, mas também, e sobretudo, porque faz crer, àquele que diz, que algo não vai bem e deve ser "gerenciado". Frequentemente, o que não funciona, o que perturba o domínio subjetivo, é sinônimo do que não está de acordo com o socialmente esperado, de modo que, se tomarmos como exemplo a sexualidade, objeto analisado por Foucault, perceberemos que aquela que não é produzida e direcionada a fins específicos, em função da moral dominante, atrelada por Foucault (2010) ao casamento, à monogamia, etc., é vista como desviante. Nesse contexto, o discurso sobre o sexo se define a partir das concepções de normal e anormal, o casal heterossexual sendo a norma e as anomalias devendo ser confessadas e purgadas, de modo que os corpos desviantes possam ser reinseridos ou incluídos no rebanho, normalizados.

Ora, esse discurso sustenta, nas sociedades ocidentais, tanto o discurso médicocientífico quanto "toda uma série de procedimentos institucionalizados de revelação da sexualidade: a psiquiatria, a psicanálise, a sexologia" (FOUCAULT, 2001, p. 214). Deve-se contudo, considerar que essa ação não é linear nem direta, pois a economia da penitência católica passou por diversas transformações (de sanções jurídicas a punições simbólicas) ao longo da história. Se essa técnica de saber-poder perdura até nossos dias e se se estende a diversas esferas, segundo a hipótese foucaultiana, certamente ela não mantém sua configuração inicial, o que nos leva a ressaltar que não afirmamos pura e simplesmente, assim como Foucault também não o faz, que a psicanálise, por exemplo, preza pela confissão nos moldes do cristianismo.

Pelo contrário, o autor é cauteloso ao indicar que "é a instauração no interior dos mecanismos religiosos desse imenso relato total da existência que constitui, a meu ver, de certo modo, o pano de fundo de todas as técnicas tanto de exame como de medicalização, a que vamos assistir em seguida" (FOUCAULT, 2001, p. 233, grifos nossos). Essas estratégias, como podemos ler, concentram-se sobre a discursivização de si, do corpo, do comportamento, de pensamentos, mas também daquilo que incomoda, do que não funciona como o esperado, enfim, de um sintoma. Sintoma este que, enquanto repetição, insistência, vai permitir a emergência do sujeito e, mesmo, de um sinthoma ${ }^{9}$, psicanaliticamente falando.

Contudo, entre o discurso moral cristão e a psicanálise como prática, instituição ou doutrina (MILNER, 2011, p. 100), há toda uma gama de discursos, principalmente

\footnotetext{
${ }^{9}$ Um saber-fazer ou um saber lidar com seu sintoma, o que pode se dar, como no exemplo do escritor James Joyce, por meio da arte da escrita.
} 
advindos do âmbito científico. Não se trata, portanto, de alinhar a confissão ao divã, mas de colocar em questão a incidência da (e a insistência na) confissão em outros domínios que não o religioso. O principal exemplo dado por Foucault, citando Alcuíno, pauta-se na relação médico-paciente, pois se sabe que "os médicos não poderão fazer mais nada no dia em que os doentes se recusarem a mostrar suas feridas" (FOUCAULT, 2001, p. 218). Por um deslize do significante, se empregássemos o termo psicanalistas ao invés de médicos, teríamos, talvez, um pequeno impasse nesse campo.

É verdade que, segundo Lacan (2005, p. 64), a psicanálise não exige uma confissão, pois "na análise, começa-se por explicar às pessoas que elas não estão ali para se confessar [...] elas estão ali para dizer - dizer qualquer coisa". O próprio Foucault (1988, p. 70) acrescenta que, na confissão, o sujeito da enunciação coincide com o do enunciado, não podendo se tratar, portanto, de um sujeito do inconsciente, sujeito dividido. Todavia, não é o exame de consciência em si, mas o mecanismo de incitação ao discurso - exatamente a insistência em dizer, mesmo que seja "qualquer coisa" - que está em causa nessa prática. Podemos pensar, assim, que o duelo de Foucault com a psicanálise concerne à constituição do sujeito, não por uma lógica do inconsciente, do desejo e do sexo como o inquietante enigma, a estrangeiridade inquietante, o estranhamente familiar, mas por uma "lógica da estratégia" (MENDELSOHN, 2010) e das relações com a verdade que aí são exercidas, pois essa verdade aparece em um espaço e em condições preparadas para tal. Esse embate diz respeito tanto ao sujeito ou à sexualidade como objetos de uma ciência, quanto à insistência no falar de si como aquilo que possibilita dizer a verdade, assim como aquilo que nos diz nossa verdade.

\section{SOBRE SEXUALIDADE E VERDADE: CONSIDERAÇÕES FINAIS}

É possível compreender, a partir da leitura foucaultiana realizada em $A$ vontade de saber, que a psicanálise não assume um lugar tão diferenciado daquele das ciências psi ou de outros discursos institucionais, pois compartilha com estes uma função de gerenciamento familiar e social. Ainda segundo Foucault (2001, p. 346), a psicanálise "vai aparecer como técnica de gestão do incesto infantil e de todos os seus efeitos perturbadores no espaço familiar". Ela não pode, pelo menos não na crítica realizada pelo autor nos anos setenta, ser considerada uma prática de contrapoder, pois, na demanda feita ao paciente para que fale, encontra-se uma injunção de poder que não é repressiva, mas que diz sim. No que concerne a essa questão, o filósofo acrescenta que "a instância de dominação não se encontra do lado do que fala (pois é ele o pressionado) mas do lado de quem escuta e cala; não do lado do que sabe e responde, mas do que interroga e supostamente ignora" (FOUCAULT, 1988, p. 71). Não nos esqueçamos de que, na análise, o analista cala exatamente porque é ele o sujeito suposto saber, e o analisante fala porque acredita, a priori, nada saber (não conscientemente) de seu desejo. Assim também as diversas instâncias, muitas delas abstratas, que nos instigam a falar, calam-se e, nesse sentido, seu papel como mecanismo de coerção e dominação parece ser ainda mais significativo. 
Entretanto, podemos ser levados a concluir que, se há um espaço aberto para que se fale, deve haver também a possibilidade de constituição e de prática da subjetividade na/pela linguagem. Esta que não é um código transparente, que é espessa e opaca, como aquela. Entendemos que, mesmo sua abordagem não sendo puramente linguística, Foucault não fica indiferente a essa questão, pois, segundo Lay (2013, p. 150), "toda estratégia de poder é uma estratégia de linguagem"10.

Confrontados à problemática que envolve a sexualidade contemporaneamente, mantemos a pergunta: estamos diante da possibilidade de práticas constitutivas da subjetividade?

Sabemos, desde Foucault, que a sexualidade não é um instinto selvagem, para além do poder, mas uma construção subordinada a ele, produzida por regimes discursivos dos quais o discurso científico, o escolar e o psicanalítico fazem parte. Dito de outro modo, sabemos que a sexualidade não é natural, mas fabricada; domesticada ou feita selvagem, ela é produto de um feixe de discursos. Todavia, ainda a vemos tomada de modo biologizante, como uma sina que nos impõe a natureza. O homossexual, por exemplo, retomando o termo de Foucault, não deixou de ser uma "espécie". Prova disso são as diversas campanhas em prol da "tolerância", concepção que merece uma análise por si só. Em uma delas, disseminada em diversas línguas, indaga-se aos participantes se se nasce ou se se escolhe ser homossexual. A cada vez que o interlocutor responde ser esta uma escolha, a pergunta seguinte é: “quando você escolheu ser heterossexual?". Também já é conhecido certo pronunciamento do médico Drauzio Varella sobre a homossexualidade, que, como uma questão biológica, pensa-se, deve ser assunto para a medicina. "A sexualidade é. Ela se impõe", afirma categoricamente o médico, reproduzindo as relações de poder entre o discurso médico e a produção da sexualidade, discutida tantas vezes por Foucault.

O efeito de sentido produzido ou, ao menos, autorizado por questões dessa ordem, é o de que a sexualidade não só não possui nenhuma carga sócio-histórico-cultural, mas, sendo puramente genética, frente a ela o sujeito não tem escolha, não há opção, ou melhor, as opções se reduzem, nas redes sociais, por exemplo, a uma identificação linguística descarnada: "qual pronome você prefere? Masculino, feminino ou neutro?". Parece não haver, portanto, saída, e o sexo é visto não só como ponto central, mas também como uma fatalidade. Deve-se confessar sua homo, hetero, bi, transexualidade, enquanto indivíduo constituído biológica e, no máximo, psiquicamente, cuja dimensão discursiva é escamoteada. Daí a enxurrada de escândalos dos quais a mídia tem se servido, a respeito de famosos que "assumiram" sua sexualidade. Daí também as relações ditas homoafetivas tão esperadas e, finalmente, mostradas na televisão aberta.

Se acreditamos estarmos diante da liberdade que nos propiciam esses discursos, devemos ao menos nos indagar sobre qual concepção de liberdade estes se fundam. Cremos que estamos a um passo de sair de uma sociedade repressiva e disciplinar, mas alguma vez pensamos que não sairemos do dispositivo de sexualidade em que fomos pegos? De acordo com Mendelsohn (2010),

\footnotetext{
${ }^{10}$ « toute stratégie de pouvoir est une stratégie de langage ».
} 
Foucault aborda a questão da sexualidade por um viés que testemunha o modo pelo qual a sequência sujeito/verdade é, efetivamente, herdeira daquelas que a precederam saber/poder e verdade/poder: o sexual aparece como o registro, por excelência, onde é preciso dizer a verdade e onde, correlativamente, dizer a verdade é revelar o que se tem de mais singular (MENDELSOHN, 2010, p. 145, grifo do autor).

Contudo, o desafio ético de uma prática da liberdade está em não restringir, enquanto sujeito, a primeira díade às anteriores. Uma forma possível seria indagar-se: dizer a verdade, ou dizer tudo, sobre o domínio da sexualidade é revelar o que se tem de mais singular ou se trata de uma submissão à "violência do pensamento identitário [...] a imposição de que o sujeito, o indivíduo tenha uma só verdade, uma essência, um corpo e uma alma decifrados em suas verdades mais recônditas" (ALBUQUERQUE JÚNIOR, 2013 , p. 4)? Foucault (2014, p. 251) responde a essa questão, afirmando que nossa postura frente ao problema da identidade deve ser a de nos afirmarmos, sempre, como seres únicos, pois a sexualidade "é nossa própria criação, muito mais do que a descoberta de um aspecto secreto de nosso desejo. Devemos compreender que, com nossos desejos, através deles, se instauram novas formas de relações, novas formas de amor e novas formas de criação".

Quando, no fim de $A$ vontade de saber, e na entrevista concedida em 1982, o autor insiste sobre o corpo e os prazeres como uma possibilidade de resistência ao dispositivo de sexualidade, é preciso refletir sobre essa proposição em relação ao âmbito das ciências psi, mas também em relação ao que pensamos, ao que sabemos e ao que pensamos não saber sobre nós mesmos. Talvez, a principal tarefa que nos deixa Foucault seja a de explorar que papel a dessexualização do prazer exerceria na constituição subjetiva contemporânea. Há outros quereres, há outras formas de prazer que não restringem e não se restringem à sexualidade. É preciso expandir essas fronteiras, essas margens, tentando, na medida do possível, duvidar dessa sexualidade fal(t)ante que nos é atribuída. Responder por essa escolha implica considerar que a sexualidade "é mais um processo que se inscreve na necessidade, para nós, hoje, de criar uma nova vida cultural sob pretexto de nossas escolhas sexuais" (FOUCAULT, 2014, p. 252). Essa é, efetivamente, uma opção, que equivaleria ao grito sob a ducha fria: "sim, sim! Sou louco [...] mas asseguro, no entanto, que ouvi vozes e vi inimigos ao meu redor". Como o senhor A., também não seremos curados, mas podemos tentar exercer "o princípio de uma crítica e de uma criação permanente de nós mesmos" (FOUCAULT, 2008, p. 346). Jamais falaremos de fora das redes de poder, mas, com sorte, talvez sejamos personagens de algum relato. Nada de puramente novo, como também já sabemos, desde Foucault.

\section{REFERÊNCIAS}

ALBUQUERQUE JÚNIOR, D. M. Vozes sem rosto, sombrias silhuetas: a contribuição da publicação do livro Vigiar e punir de Michel Foucault para a historiografia brasileira. In: SIMPÓSIO LINGUAGENS E IDENTIDADE DA/NA AMAZÔNIA SUL-OCIDENTAL, 7., 2013, Rio Branco. Disponível em: $<$ http://simposioufac.blogspot.com.br/2013/08/durval-muniz-de-albuquerque-junior.html $>$. Acesso em: 20 jun. 2014. 
BARTHES, R. Aula: aula inaugural da cadeira de semiologia literária do Colégio de França. São Paulo: Cultrix, 2007.

BURGUIERE, A. Michel Foucault: la preuve par l'aveu. In: BERT, J. -F. (Org.). La volonté de savoir de Michel Foucault: Regards critiques, 1976-1979. Caen: Presses Universitaires, 2013. p. 135-144.

CAMARGO, L. F. E.; AGUIAR, F. Foucault e Lacan: o sujeito, o saber e a verdade. Revista Aurora, Curitiba, v. 21, n. 29, p. 531-544, jul./dez. 2009.

DERRIDA, J. Fazer justiça a Freud. In: ROUDINESCO, E. et alii (Orgs.). Foucault: leituras da História da Loucura. Rio de Janeiro: Relume Dumará, 1994. p. 81-82.

FOUCAULT, M. A vontade de saber. História da sexualidade, vol. I. Trad. Maria Thereza Albuquerque e Guilhon Albuquerque. Rio de Janeiro: Graal, 1988.

. As palavras e as coisas. Trad. Salma Tannus Muchail. São Paulo: Martins Fontes, 1999.

Os anormais. Trad. Eduardo Brandão. São Paulo: Martins Fontes, 2001.

O que são as luzes. In: FOUCAULT, M. Ditos e escritos. Vol. II. Trad. Elisa Monteiro. Rio de

Janeiro: Forense Universitária, 2008. 2009. A arqueologia do saber. Trad. Luiz Felipe Baeta Neves. Rio de Janeiro: Forense Universitária,

Sexualidade e poder. Conferência na Universidade de Tóquio, 1978. In: FOUCAULT, M. Ditos e escritos. Vol. V. Trad. Elisa Monteiro e Inês Barbosa. Rio de Janeiro: Forense Universitária, 2010. p. 56-76.

L'origine de l'herméneutique de soi. Mayenne: Vrin, 2013.

Michel Foucault, uma entrevista: sexo, poder e a política da identidade. In: FOUCAULT, M. Ditos e escritos. Vol. IX. Tradução Abner Chiquieri. Rio de Janeiro: Forense Universitária, 2014. p. 251 263.

FREUD, S. L'inquiétante étrangeté. Paris: Gallimard, 1933.

GOLDENBERG, R. Da talking cure ao discurso sem palavras. In: LEITE, N.; MILÁN-RAMOS, G.; SALZANO MORAES, M. R. (Orgs.). De um discurso sem palavras. Campinas: Mercado de Letras, 2012. p. 19-42.

GROS, F. Michel Foucault, une philosophie de la vérité. Sem paginação. Disponível em: $<$ http://1libertaire.free.fr/IntroPhiloFoucault.html>. Acesso em: 20 dez. 2013.

LACAN, J. O triunfo da religião. Trad. Andre Telles. Rio de Janeiro: Jorge Zahar, 2005.

LAY, M. L'aveu du sexe. In: BERT, J. -F. (Org.). La volonté de savoir de Michel Foucault: Regards critiques, 1976-1979. Caen: Presses Universitaires, 2013. p. 147-151.

MENDELSOHN, S. Foucault avec Lacan: le sujet en acte. Filozofski vestnik, Letnik XXXI, Stevilka 2, p. 139-169, 2010.

MILNER, J. -C. Clartés de tout: de Lacan à Marx, d'Aristote à Mao. Éditions Verdier, 2011.

L'universel en éclats. Éditions Verdier, 2014.

ROUDINESCO, E. Filósofos na tormenta. Trad. André Telles. Rio de Janeiro: Jorge Zahar, 2007.

SENELLART, M. Foucault, sexualité et vérité: relire La volonté de savoir. Séminaire de philosophie politique. École Normale Supérieure de Lyon. Anotações pessoais da aula intitulada Des anormaux à La volonté de savoir (I): le discours chrétien de la chair, ministrada em 02 dez. 2013.

\section{Recebido em: 31/08/14. Aprovado em: 12/03/15.}

Title: The incidence and the insistence of the truth in the discourse: notes to reread The will of knowledge

Author: Marluza da Rosa

Abstract: In this essay, we propose a reading path that focuses on the relationship between Foucault and psychoanalysis, often seen as ambivalent. We focus on the criticism developed by the author in The will of knowledge, trying to link the problem of producing the truth and the incidence and insistence of/in the discourse. This relation allows us to affirm that it is only because there is a demand of an exhaustive speech in particular conditions, that the subject and the truth, in psychoanalytic terms, emerge, which leads us to understand not only that the truth is permeated by the fundamental experience of 
language, but also that it is usually generated by fields of knowledge, and does not preexist the discourse.

Keywords: Discourse. Psychoanalysis. Truth.

Título: La incidencia y la insistencia de la verdad en el discurso: notas para releer La voluntad de saber

Autor: Marluza da Rosa

Resumen: En este artículo proponemos una ruta de lectura que incide sobre la relación, frecuentemente tenida como ambivalente, entre Foucault y el psicoanálisis. Partimos de la crítica desarrollada por el autor en La voluntad de saber, buscando articular el problema de la producción de la verdad a la incidencia y a la insistencia del/en el discurso. Esta articulación permite reafirmar que es porque hay demanda de un decir exhaustivo, y en dadas condiciones, que el sujeto y a verdad, en términos psicoanaliticos, emergen, lo que nos conduce a comprender no solo que las verdades de nuestro tiempo y de nuestra sociedad son impregnadas por la experiencia fundamental de la lenguaje, pero también que ellas son, en grande medida, producidas por campos de saber, no preexistiendo, así, al discurso.

Palabras-clave: Discurso. Psicoanálisis. Verdad. 